\title{
El riesgo como dispositivo de gobierno: neoprudencialismo y subjetivación
}

\section{Risk as a device of governance: neo-prudentialism and subjectivation}

Mauricio Sepúlveda Galeas ${ }^{1}$

\section{Resumen}

En el presente artículo se analizan las prácticas discursivas sobre el riesgo en el contexto de los procesos de gubernamentalización neoliberal, entendiendo (problematizando) el riesgo como un dispositivo de gobierno, a través del cual se articulan procesos de objetivación y subjetivación característicos del capitalismo contemporáneo. En efecto, lo que se demanda hoy son almas capacitadas o, dicho de otro modo, subjetividades equipadas con las cualidades volátiles más cotizadas de la sociedad del riesgo, -responsabilidad, aguante, etc.todas ellas plasmadas o encarnadas de forma ideal en el empresario de sí, y en particular, en el homo prudens; todas cualidades que "casualmente", directa o indirectamente, se hallan integradas en la parrilla de objetivos de los programas de prevención propios del ámbito "Psi".

Palabras clave: riesgo, seguridad, gubernamentalidad, neoliberalismo, neoprudencialismo.

\begin{abstract}
This article explores the discursive practices about risk in the context of neoliberal governmentality processes, understanding (problematizing) the risk as a device of governance through which processes of objectivation and subjectivation characteristic of contemporary capitalism are articulated. Indeed, what is required today are "trained souls", or in other words, subjectivities equipped with the most
\end{abstract}

1 Psicólogo. Doctor en Antropología. Grupo de investigación en Antropología social. Universidad Rovira i Virgili. Tarragona (España). E-mail: galeas_m@hotmail.com 
sought volatile qualities after in the risk society, -like responsibility, endurance, etc.- all reflected or ingrown ideally in the self-producing businessman, and in particular in the homo prudens. Qualities all of which "coincidentally", directly or indirectly, are integrated in the variety of objectives of the prevention programs within the "Psi"-sphere.

Key words: risk, security, governmentality, neoliberalism, neo-prudentialism.

De la cuestión del riesgo al riesgo en cuestión

En las últimas décadas, en plena expansión hegemónica del liberalismo avanzado, o neoliberalismo, la cuestión del riesgo ha ido adquiriendo de forma progresiva una presencia prominente, tanto en el habla experta como profana, instituyendo significados y formas de enunciación que involucran el conocimiento y gestión de fenómenos tan diversos entre sí, como el cuidado de la salud, la preservación de la naturaleza o el control de ciertas conductas desviadas (los llamados comportamientos de riesgo). Diversos en principio, pues tras una segunda lectura se observará cómo estos distintos fenómenos confluyen y se relacionan entre sí con tal intensidad que llegan a cristalizar en un tipo singular de formación discursiva inscrita en la genealogía del biopoder.

En efecto, por un lado, el término riesgo es un concepto que forma parte del vocabulario utilizado frecuentemente por los diferentes técnicos y especialistas implicados en su gestión y control, y por otro, forma parte del lenguaje cotidiano de las personas que por diferentes razones son expuestas a dichos fenómenos, asumiendo por ello y para ello ingentes esfuerzos, ya sea para evitarlos o bien para reducirlos. En cualquier caso, independientemente del locus diferencial de su enunciación, no cabe duda que hoy por hoy, en la llamada era de la gubernamentalidad ${ }^{2}$, la

2 Con el concepto gubernamentalidad M. Foucault se refiere a "[...] el conjunto constituido por las instituciones, los procedimientos, análisis y reflexiones, los cálculos y las tácticas que permiten ejercer esa forma bien específica, aunque muy compleja, de poder que tiene por blanco principal la población, por forma mayor de saber la economía política y por instrumento técnico esencial los dispositivos de seguridad" (2006, p. 136). 
cuestión del riesgo constituye un campo de saber/poder en torno al cual las nuevas tecnologías de gobierno se van a articular, movilizando para ello sus respectivos dispositivos de control y regulación social. Así, por ejemplo, hoy en día la palabra «riesgo» es omnipresente en las políticas socio-sanitarias y en las prácticas asistenciales, especialmente en el marco de la llamada era del Sida. Tal como subrayan diversos expertos (Leflaive, 2004), en el campo del VIH y del consumo de drogas, la noción de riesgo constituye el "pan cotidiano" conceptual de las iniciativas de prevención -tanto públicas como privadas- pero sin que la noción sea realmente comprendida y menos aún cuestionada.

En efecto, el término riesgo suele ser utilizado con diversos sentidos, los que a menudo se solapan entre sí, dependiendo de quién lo emplee, de su finalidad y de su contexto de enunciación; riesgo como peligro o amenaza (por ejemplo, las drogas); una situación o actividad que puede tener consecuencias dañinas (por ejemplo, fumar cigarrillos); riesgo como término para las consecuencias dañinas de un peligro (el riesgo de fumar es el cáncer de pulmón); o, más cercano a su significado original, riesgo como probabilidad de la ocurrencia de un (a menudo adverso) resultado (la probabilidad de tener cáncer de pulmón) (Gamma, Jerome, Liechti \& Sumnall, 2005). Y es que, en cierta medida, ello se debe a que la idea de riesgo se ha convertido en un instrumento abierto a la construcción de múltiples significados sociales. En realidad, las propias características discursivas del riesgo generalmente introducen una fuerte dosis de opacidad, dificultando su análisis, pues siendo una construcción primordialmente socio-histórica, suele concebírsele en términos a-históricos.

En otras ocasiones, la idea de riesgo tiende a exhibir la representación de un espacio social reducido, en la medida que transporta un habla despolitizada, esto es, en el sentido de la construcción de imágenes naturalizadas de las conductas y de la realidad social en general (Lupton, 1993). En este sentido, detrás de diferentes fórmulas y tipos de cálculos de riesgo, el tipo de universo semántico que caracteriza al lenguaje del riesgo es, entonces, limitado y cerrado a cualquier clase de interpelación, ya sea desde el punto de vista de sus contenidos y significados como de sus implicaciones (Lupton, 1993). 
En particular, el análisis de las prácticas discursivas sobre los riesgos en el marco de los procesos de gubernamentalización, no reduce el problema de su gestión a la esfera del Estado, sino lo inserta en una cuestión más amplia relacionada con las nuevas racionalidades y tecnologías de gobierno de cuño neoliberal. Al mismo tiempo, posibilita entender las modernas estrategias de gubernamentalidad como expresión del poder en transformación, poder que en tanto realidad creativa es capaz de adaptarse a las nuevas realidades históricas, produciendo a su vez, consecuencias sobre esas mismas realidades, a través de sus múltiples formas de objetivación y de subjetivación (San Martín, 2009).

Ahora bien, los cambios y mutaciones en la significación del riesgo, arriba señalados, nos informan cómo mediante este concepto se entrelazan procesos epistémicos, morales y tecnológicos inscritos en la gramática del poder. De acuerdo a Foucault, los dispositivos de seguridad expresan, a partir del siglo XVIII, un modo de intervención del poder (biopoder/ biopolíticas) que complementa el marco disciplinario dirigiéndose, no ya al cuerpo del individuo, sino a la idea de peligrosidad: a la gestión de una serie de eventos probables que se refieren a los grupos de población en que el individuo se inscribe (San Martín, 2009). Como señala Ian Hacking (1991) se trata de una racionalidad de gobierno posibilitada por el desarrollo del conocimiento estadístico y los cálculos de probabilidad desplegada a partir del siglo XVIII; momento en el que "el poder descubre el cálculo de riesgos, es decir, la prevención de peligros con base a la distribución de su probabilidad” (San Martín, 2009, p. 52).

Desde un punto de vista genealógico, la noción de riesgo, desde los albores de la modernidad, se encuentra fuertemente imbricada a la cuestión del peligro (seguridad), y este con la cuestión del gobierno de las poblaciones. Por ello mismo, desde una perspectiva político-epistemológica, el riesgo, no solo será una manera moderna de considerar el peligro, atribuyéndole una probabilidad en un contexto de incertidumbre, sino que además constituye un dispositivo de gobierno inscrito en la gramática del biopoder. De hecho, los riesgos (o peligros) no son datos absolutos, pues existe una selección y una construcción social de los mismos, a través de los cuales estos son moralizados y politizados respectivamente (Douglas, 
1991). Parafraseando a Foucault, quien afirmará que no hay liberalismo sin cultura del peligro, hoy se puede decir que no hay neoliberalismo sin cultura del riesgo. Si la estimulación del temor al peligro, en cierto modo, fue la condición, el correlato psicológico y cultural interno del liberalismo (Foucault, 2006) el discurso "riesgosista" va a ser su equivalente neoliberal.

En el marco de nuestro planteamiento, esto último tendrá una doble implicancia. Por un lado, desde una perspectiva histórica -desde un eje conocimiento/verdad-implica situar la significación negativa del riesgo en un contexto histórico de larga duración, pudiendo ser entendida como un efecto asociado a la codificación moderna del peligro en clave de manejo y control de la incertidumbre y la inseguridad. Por otro lado, implica situar la significación negativa del riesgo en su dimensión genealógica -desde un eje discurso/poder-, esto es, en tanto efecto de determinadas prácticas discursivas y enfrentamiento del poder -es decir, tecnologías de gobiernoque caracterizan la especificidad que adquiere su construcción social, explicando cómo este es capaz de reinventarse ante nuevas condiciones de posibilidad. En otras palabras, cómo se reconfigura en determinados momentos históricos. Desde esta doble perspectiva, el análisis del binomio "riesgo-peligro" en el presente, resulta no solo pertinente, sino que además necesario, toda vez que este se comporta como un dispositivo de saber/ poder a través del cual se entretejen discursos, instituciones, enunciados científicos, proposiciones filosóficas, morales, etc. en un contexto signado por la globalización y la post-modernización, donde la relación "EstadoSociedad" y las problemáticas del gobierno, se hallan inmersas en una profunda reconfiguración (Sepúlveda, 2011).

La gestión del riesgo: nuevas racionalidades... nuevas tecnologías

El análisis de las prácticas discursivas contemporáneas sobre el riesgo, nos advierte de cambios significativos experimentados tanto a nivel de su racionalidad política como de sus tecnologías. Dichas transformaciones llevan una doble marca; por un lado, la huella del paso de una racionalidad welfarista a una racionalidad neoliberal; y, por otro lado, la del tránsito de las sociedades disciplinarias a las sociedades de control; doble marca 
que performará la semblanza del poder, difuminándolo y haciendo que el sujeto de gobierno deje de ser aquel "sujeto dócil" y "disciplinado" para ahora ser el sujeto "libre" y "autónomo".

En cuanto al desplazamiento en las racionalidades políticas, cabe tener presente que la racionalidad welfarista es propia del Estado de Bienestar, la cual se gestó institucionalmente a finales del siglo XIX y fue dominante durante todo el periodo que media entre el final de la Segunda Guerra Mundial y mediados de los ochenta e inicios de los noventa (Ampudia de Haro, 2006). De acuerdo a dicha racionalidad, será el Estado el encargado de asegurar el pleno empleo, el progreso y crecimiento económico, el sistema de la seguridad social, el acceso a la salud, a la vivienda y el responsable de regular las posibilidades educativas, todo ello mediante el establecimiento y redistribución de impuestos y su propia acción inversora y planificadora (Ampudia de Haro, 2006). Desde esta racionalidad, la cuestión fundamental será garantizar un marco de bienestar generalizado, promocionando la igualdad de oportunidades, la responsabilidad y la socialización de los riesgos.

Del otro lado, la racionalidad politica neoliberal, prescindiendo de la pretensión reguladora, planificadora y previsora del Estado de Bienestar y del welfarismo, apostará por economizar, en la máxima medida de lo posible, el ejercicio del poder (Ampudia de Haro, 2006). Como bien advierte Francisco Vázquez (2005) en la gubernamentalidad neoliberal, la cuestión es cómo gobernar, con la máxima seguridad, el mercado y los procesos vitales de la población, limitando al mínimo la acción directa de Estado. De ahí que se enfatice la necesidad de que sean los propios individuos quienes se aseguren personalmente la provisión de determinados bienes y servicios, argumentando que con ello lo que se busca es combatir la llamada "cultura de la dependencia", en tanto esto último representa uno de los principales blancos de la crítica neoliberal. De otro modo, en términos prácticos, la racionalidad política neoliberal comporta la paulatina privatización de los servicios de salud, educación, seguridad, pensiones, seguros, etc., bienes y servicios en general, "de los que ahora realizará acopio el individuo a título personal acudiendo al mercado para su compra; bienes y servicios dependientes de su capacidad y 
solvencia económicas" (Ampudia de Haro, 2006, p. 67). Esto, de ahora en adelante, correrá aparejado a la privatización de empresas antańo estatales, a la gestión con arreglo a modelos privados de empresas públicas y a una creciente flexibilidad laboral y contractual (Ampudia de Haro, 2006).

En cuanto al desplazamiento hacia las sociedades de control, este se halla fuertemente relacionado al punto anterior, pues refiere a las nuevas formas del ejercicio del poder que sugieren una serie de discontinuidades caracterizadas por la crisis del paradigma disciplinario, tal y como alcanzó su esplendor bajo el welfare. A grandes rasgos, tres líneas de fuerza caracterizarán el paradigma disciplinario: una filosofía de integración derivada de un sistema productivo siempre carente de trabajo vivo; un entramado de formas de saber dirigidas a una introspección en el sujeto con el objetivo de su normalización, lo que significaría una intervención centrada en el cuerpo y el alma del individuo; y un sistema de control que privilegia los entornos cerrados de tratamiento donde llevara a cabo esa ortopedia social (San Martín, 2009). Y aunque el mismo Foucault, a la hora de analizar el ejercicio gubernamental del poder dirigido a la regulación de agregados de población más que a la normalización de individuos aislados, dará cuenta de dicho desplazamiento, será Gilles Deleuze (1999) quien mejor retratará el tránsito hacia las sociedades de control, las que se caracterizarán por el declive de las instituciones de encierro -en su filosofía, no en su existencia-, la creciente colonización del espacio abierto por los dispositivos de control - "control al aire libre” dirá Deleuze (1999)-, el paso de los moldes disciplinarios a las modulaciones, el paso del individuo-cuerpo a la cifra, al dato, la sustitución de la fábrica por la empresa -la empresa es un alma, es etérea (Deleuze, 1999)-, el paso del examen y la observación analógica, a la digitalización y la virtualidad.

Como consecuencia de las formas de gobierno neoliberal se producirá una fuerte crisis de Estado-nación, lo que va a reconfigurar el vínculo, el tipo de relación del Estado y las instituciones, del Estado y los objetos/sujetos de gobierno, de lo público y lo privado, situando en el centro de la relación los principios de la gestión eficiente o eficiencia en la gestión como el "quid" o clave de la nueva gestión. En ese horizonte, emergerá la figura del homo prudens, artefacto semiótico que expresa y 
representa una subjetividad modelada y canalizada por una racionalidad de gobierno neoliberal, pero que en tanto tipo ideal, permite articular un análisis crítico de los patrones interiorizados y culturalizados de coerción blanda que se alterna y entrecruzan de forma segmentada con el despliegue del brazo penal o coerción dura, discriminación estratégica que caracteriza la gubernamentalidad biopolítica contemporánea.

\section{"Homo prudens" y gestión de riesgos}

De Marinis (1999) señala que sería un error ver en el nuevo sujeto construido y estimulado por el neoliberalismo una simple reedición del viejo y decimonónico homo economicus del liberalismo clásico. Cabe recordar que el liberalismo clásico identificaba la acción estatal con una tarea negativa, pues este debía eliminar los obstáculos que impedían el autogobierno espontáneo de los procesos sociales y de un tipo de individualidad concebido al modo de la Naturaleza (Vázquez, 2005). El homo economicus era el individuo que elegía libremente, buscando la maximización de su interés mediante el cálculo de su intervención en términos puramente utilitaristas (Vázquez, 2005). En este sentido, el liberalismo clásico era vocacionalmente naturalista; el mercado (autorregulado), la población y la sociedad civil (autónomas), e incluso el mismo homo economicus, era una realidad "cuasinatural" que se encontraban artificialmente constreñidas por el pesado reglamento del Estado de policía. En cambio, para la perspectiva liberal avanzada, o neoliberal, se va tratar de realidades que poseen un talante eminentemente constructivista. En efecto, el juego libre y competitivo del mercado, la autonomía de los individuos y de la sociedad civil, no constituyen un hecho de la Naturaleza (Vázquez, 2005). Antes bien, se trata de realidades programables, realidades o artefactos construidos o por construir. Si el individuo liberal estaba constituido por intereses naturales y preestablecidos como la búsqueda del placer y evitación del dolor, la maximización del beneficio personal, etc., el individuo promovido por la gubernamentalidad neoliberal necesitará ser producido, fabricado. Se trata de convertir, entonces, al individuo dependiente y necesitado, al ciudadano social, ligado a la colectividad por mecanismos estatales de solidaridad, 
en un individuo activo y autorresponsable, capaz de elegir por sí mismo y de sacarle el máximo partido a sus recursos personales en la búsqueda de un estilo propio y singular (Vázquez, 2005). El nuevo sujeto no es un mero calculador de sus intervenciones en términos puramente utilitaristas, sino más bien, como lo señala Pat O`Malley (1996), se trata de un tipo humano que puede ser significado como homo prudens. En efecto, en el marco del nuevo prudencialismo, "el homo prudens buscará en el mercado (y podrá encontrar, en concordancia con sus específica capacidad de adquisición de bienes y servicios) las variadas ofertas disponibles para satisfacer sus necesidades vitales de seguridad, placer y bienestar personal y existencial" (De Marinis, 1999, p. 94). El homo prudens encarna una subjetividad afín con las racionalidades políticas neoliberales, así como con las nuevas tecnologías del riesgo. En cuanto a su primera afinidad, habrá que señalar que los modos de subjetivación del homo prudens se hallan codificados conforme al orden molar de "el empresario de sî". En efecto, tal como hemos señalado en párrafos anteriores, en consonancia con su intención de economizar el ejercicio del poder, lo que se pretende desde el liberalismo avanzado es que el individuo aporte la mayor cantidad de energía aplicada a su autogobierno, que sea personalmente autónomo para desarrollar un proyecto de vida, optando racionalmente entre una amplia gama de opciones, y de este modo, pueda autogestionar su individualidad (Ampudia de Haro, 2006). Así, se abre una amplia gama de posibilidades reflexivas y creativas para poder diseñar su proyecto de vida, el cual se diseñará conforme al diagrama Psi de la felicidad y del bienestar que preconiza el código de la civilización reflexiva (Ampudia de Haro, 2006) en la modernidad tardía. Este diagrama integra una serie de rasgos de la cultura "psi” como la autoaceptación física y psíquica, la autenticidad, la no deberización, o la autodependencia, entre otros, los cuales serán recogidos e integrados en los kit preventivos usados en, por ejemplo, el campo de las drogas -entre muchos otros fenómenos etiquetados como problemas sociales- en clave de habilidades para la vida o fortalecimiento de la autoestima. Estos son rasgos o atributos característicos de la cultura terapéutica ampliamente difundida a través de sus diversos dispositivos orientados a la autoayuda y a la ayuda de otros. En clave foucaultiana, se trata de la potenciación de un diagrama Psi en el marco 
de la cultura terapéutica que conecta con el desarrollo de las tecnologías políticas de la individualidad; tecnologías que las autoridades, entre otros agentes, ponen en marcha al entender que es deseable educar al ciudadano en técnicas de autogobierno. De ahí que el diagrama Psi y sus técnicas de regulación de sí, modulan las subjetividades en consonancia con las políticas neoliberales contemporáneas.

En consonancia con el objetivo neoliberal de sacarle máximo partido a los recursos personales, se visualiza una segunda filiación del homo prudens, ahora inscrita en la genealogía de las tecnologías del riesgo. Ciertamente, la gubernamentalidad liberal avanzada tiende a reemplazar la tecnología de riesgos localizada en los vínculos colectivos por estrategias de autorresponsabilización. Pero cuidado, si bien puede parecer que nos encontramos ante una reedición del viejo prudencialismo de los siglos XIX y XX, lo cierto es que dista mucho de serlo. En efecto, el homo prudens del liberalismo avanzado, nos remite y nos revela a la vez, las características definitorias del contexto histórico en que opera; esto es el neoprudencialismo.

$\mathrm{Al}$ respecto, Françoise Ewald (1997), partiendo de la premisa que la prudencia define el comportamiento humano frente a la incertidumbre, sostiene que en los dos últimos siglos se han sucedido tres grandes dispositivos de prudencia: el dispositivo de responsabilidad, en base a la falta, que predominó en el siglo XIX; el dispositivo de solidaridad, en base al riesgo, que se desarrolló a lo largo del siglo XX. Ahora bien, en el presente, una serie de hechos sociológicos, jurídicos y normativos llevan a Ewald (1997) a pensar que estamos siendo protagonistas de una profunda transformación que anuncia la reformulación del compromiso de la responsabilidad y la emergencia del dispositivo de seguridad, cuyo nacimiento se produciría en torno al reconocimiento del principio de precaución. Ahora bien, según este autor, a cada de uno de estos dispositivos le corresponde una actitud; si en el paradigma de la solidaridad es la previsión la actitud dominante, en el paradigma de la responsabilidad será la prevención y en el de seguridad, como ya hemos dicho, será el de la precaución. Sin embargo, conviene precisar que estas tres formaciones, lejos de ser incompatibles, resultan complementarias: "No se trata de tres mundos que se sucederían en el tiempo, 
se trata más bien de tres actitudes respecto a la incertidumbre y desarrolladas en tres momentos distintos en el tiempo" (Ewald, 1997, p. 28).

En términos generales el paradigma o dispositivo de responsabilidad refiere a una determinada economía de derechos y deberes en la cual la parte de las obligaciones morales -hacia uno mismo y los demás-es más importante que las obligaciones jurídicas. Es decir que este paradigma, arraigado en una filosofía liberal, privilegia la libertad y la voluntad individual antes que la obligación. Aquí las obligaciones legales hacia los demás se resumen en la norma de "no perjudicar a los demás" y la virtud ocupa un lugar preponderante en la doble forma de la previsión (hacia uno mismo) y de la benevolencia (hacia los demás) (Ewald, 1997). El dispositivo o paradigma de responsabilidad corresponde al Estado de Providencia, en el cual se amplían las obligaciones legales que tienden a cubrir a las de tipo moral. Se acompaña de una ampliación y multiplicación de derechos sociales y del reconocimiento del derecho general de indemnización frente a cualquier evento de la vida. "Es contemporánea de una utopía científica técnica según la cual la sociedad tendría la posibilidad de un dominio sobre sí misma, y el saber tendría un control indefinido sobre el poder" (Ewald, 1997, p. 14). Filosóficamente es indisociable del imperativo de la prevención (de las enfermedades, del crimen, de los accidentes, de la inseguridad social y de la pobreza). El paradigma de la seguridad reconfigura y pone en marcha una nueva economía de derechos y deberes. Si la noción de riesgo, unida a las competencias otorgadas a la pericia científica, era suficiente para determinar la situación de inseguridad, este nuevo paradigma reintroduce la cuestión de la incertidumbre, pero de una forma diferente al modo en el que lo hacían los paradigmas predecesores. También pondrá de manifiesto una relación profundamente transformada con una ciencia a la que interroga más por las dudas que plantea y menos por los saberes que ofrece. Aquí "las obligaciones morales adoptan la forma de la ética, y el principio de responsabilidad queda reflejado en torno a la nueva noción de precaución" (Ewald, 1997, p. 14).

Sobre la base de este diagrama, se observará que la lógica neoprudencial que orienta al homo prudens se aleja en varios sentidos del veteroprudencialismo del siglo XIX y XX. Si bien este último hacía 
hincapié en la responsabilidad individual, lo hacía con matices distintivos, pues los criterios de gestión y regulación de la conducta y la emocionalidad remitían por lo general a la pericia de expertos vinculados al aparato de gobierno (saber profesional burocratizado). Será, por ejemplo, el caso de los higienistas y pedagogos que, basándose en el discurso científico de la época, lograrán vertebrar sus influencias a través de sus publicaciones que harían llegar a las escuelas y centros de instrucción con el propósito de inculcar patrones conductuales y emocionales en pro de la autorregulación y el autogobierno (Ampudia de Haro, 2007). Esa era la lógica que trasuntaba el viejo prudencialismo, cuando la filantropía y las instituciones correccionales trataban de inculcar en las clases trabajadoras las virtudes del ahorro, la sobriedad y la anticipación calculada de las incertidumbres venideras. Como veremos a continuación, el nuevo prudencialismo se distancia del anterior tanto epistemológica como políticamente.

En términos epistemológicos, la emergencia del paradigma de la seguridad que opera bajo el principio de la precaución supone una nueva relación de la ciencia y el conocimiento. Esta refiere a una epistemología de la relatividad del conocimiento científico y, en consecuencia, a una ética sofisticada y escéptica. Dicha epistemología invita a anticiparse a lo que todavía no se sabe, a tener en cuenta hipótesis dudosas, simples sospechas, a tomar en serio las previsiones más descabelladas, los avisos de profetas, falsos o verdaderos, etc. (Ewald, 1997). En efecto, mientras que la actitud de prevención que precede a la precaución (paradigma solidario-industrial) supone una relación con el saber que garantice la veracidad de los saberes, la hipótesis de la precaución invita a convertir al genio maligno más engañoso en un continuo compañero. El desgaste, el retroceso, la erosión de la ilusión de un posible control de la ciencia por sí va a ser más que evidente (Ewald, 1997). Antes parecía que las ciencias de la ingeniería disponían de una especie de poder de autocontrol infinito. Parecía también que a medida que iban surgiendo nuevos peligros se daban nuevas posibilidades de controlarlos y reducirlos. Como bien dice Ewald (1997) "Vivíamos en la hipótesis de una adecuación siempre posible entre saber y poder" (p. 25). En la práctica, esto quiere decir que dentro de la lógica veteroprudencialista la vinculación autoridad política y pericia del experto era muy fuerte. Esta 
se traducía habitualmente en el peritaje como medio, no solo de validación, sino también de inducción de determinadas pautas de comportamiento autorregulado. La voz del experto, siempre vinculada al Estado, fungía como criterio indiscutible de objetivación a partir del cual se socializan los riesgos y se proporciona un margen de seguridad para su gestión.

Ahora bien, a partir de la década de los ochenta -condicionado por una serie de problemas contemporáneos relacionados con la seguridad en el campo de la medicina, el medio ambiente y desarrollo tecnológico (Ewald, 1997), o como diría Beck, condicionado por la emergencia de una serie de riesgos civilizatorios - se vivirá un marcado retorno de la incertidumbre científica en las lógicas del saber. Dicho desde su anverso, esta ausencia de certidumbres refiere a una situación en la que no se puede formular -entre una causa y su efecto- más que una relación de posibilidades, de eventualidad o de probabilidad, sin que se pueda tener la prueba de su validez. Esto va a significar que se reintroduzca una lógica de decisión "pura", pues ya no podrá ampararse, ni en el conocimiento experto, ni en una moral ligada a la aplicación de un marco preexistente.

Este nuevo escenario de "catástrofes ingobernables" conjuntadas con la irrupción de racionalidades neoliberales de gobierno y al desmantelamiento del Estado de Bienestar, va a terminar por acabar con uno de los pilares básicos del veteroprudencialismo: el cuerpo de expertos sociales. En efecto, este último se va a fracturar en una pluralidad inabarcable de expertos -en adicciones, sexualidad, alimentación, niños, inmigrantes, ancianos, matrimonios, relaciones sentimentales, riesgos laborales, etc.-, "ante lo cual el individuo no tiene más remedio que convertirse en un experto de sí mismo" (Ampudia de Haro, 2007, p. 70).

Ahora bien, este desplazamiento a nivel epistémico introduce una fractura en la relación del "saber/poder" y el "orden/social", pues el primero hasta ahora proveía de certitudes, certezas y certidumbres que estabilizaban el sistema, es decir, inyectaba negüentropia hacia el segundo (orden/social). La producción de saber se apoyaba hasta ahora en cierto monopolio del discurso de la verdad (la ciencia), cuya producción se organizaba sobre la base de un esquema altamente centralizado y jerarquizado. Tras estos quiebres, como bien señala Beck (1998), de 
pronto la opinión pública y la política empiezan a ejercer el derecho a voz en el ámbito íntimo del management empresarial, en la planificación de la producción, en el equipamiento técnico, etc., no solo en relación a las consecuencias para la salud de la naturaleza y del ser humano, sino también en relación a sus efectos secundarios sociales, económicos y políticos. Hablamos de hundimiento de mercados, desvalorización del capital, controles burocráticos de las decisiones empresariales, apertura de nuevos mercados, costes monstruosos, procedimientos judiciales, etc. (Beck, 1998). Se produce entonces una suerte de implosión en el diagrama de saber -el cual se descentra, fragmenta y capilariza- que tendrá unas consecuencias imprevistas. Ciertamente, la fractura del cuerpo de expertos sociales implicará no solo su fragmentación sino también su entrada masiva a un mercado de consumo antes centralizado en los distintos aparatos del Estado. Esto significará la inflación de una oferta especializada a la cual tendrá que recurrir (consumir) el nuevo sujeto prudencial. Sin embargo, no es menos cierto, que también implicará la apertura -en la multiplicidadde nuevos espacios políticos y epistémicos donde se podrá agenciar la nueva acción social (nuevos locus de enunciación). La implosión del saber científico, en cierto modo, desnuda la arbitrariedad de la verdad y desactiva su monopolio. Lo que hasta ese momento se había considerado apolítico se vuelve político, y por tanto, puede devenir en objeto de reapropiación por parte de un saber minoritario. Para retomar una expresión de Deleuze y Guattari (2002) diríamos que se activa un proceso de desterritorialización en ciertos ámbitos del saber, abriéndose espacios para la articulación de otros saberes que puedan maximizar las oportunidades de contradicción. O dicho de otro modo, abriéndose la posibilidad para la entrada en escena de saberes otros cuyo propósito sea la minimización de la dominación.

En términos políticos, la distancia política entre ambos prudencialismos tiene relación con la economía política del riesgo. Ulrich Beck (1998) advierte que si bien los riesgos en la sociedad industrial concernían principalmente a las clases populares, ahora en el presente, la mundialización de los peligros medioambientales, el fin del pleno empleo y el desmantelamiento del Estado del Bienestar han expandido el riesgo a todos los sectores. En palabras de Beck "los riesgos de la modernización 
afectan más tarde o más temprano también a quienes los producen o se benefician de ellos. Contienen un efecto búmeran que hace saltar por los aires el esquema de clases" (Beck, 1998, p. 29). Esto, según el mismo Beck, no excluye que muchos riesgos estén repartidos de una manera específica de las capas o clases. En esa dirección señala que:

[...] hay amplias zonas de solapamiento entre la sociedad de clases y la sociedad del riesgo. La historia del reparto de los riesgos muestra que éstos siguen, al igual que las riquezas, el esquema de clases, pero al revés: las riquezas se acumulan arriba, los riesgos abajo (Beck, 1998, p. 41).

Por tanto, los riesgos parecen fortalecer y no suprimir la sociedad de clases. A la insuficiencia de los suministros se añade la falta de seguridad y una sobreabundancia de riesgos que habría que evitar o minimizar. Frente a ello, aquellos situados en lo alto de la pirámide social pueden comprarse la seguridad y la libertad respecto del riesgo. Esta suerte de Ley de reparto de los riesgos específico de las clases y, por tanto, "de la agudización de los contrastes de clase mediante la concentración de los riesgos en los pobres y débiles estuvo en vigor durante mucho tiempo y sigue estándolo hoy para algunas dimensiones centrales del riesgo" (Beck, 1998, p. 50). Algo muy diferente e inverso ocurre con las incertidumbres manufacturadas o riesgos de la modernización cuya extensión relativiza las diferencias y los límites sociales. Según Beck (1998) esto "queda más claro aún si tomamos en consideración el modelo especial de reparto de los riesgos de la modernización: éstos poseen una tendencia inmanente a la globalización” (p. 42). Extremando esta línea argumental Beck llegará a la controversial conclusión "que las sociedades del riesgo no son sociedades de clases; sus situaciones de peligro no se pueden pensar como situaciones de clases, ni sus conflictos como conflictos de clases" (1998, p. 42). Controversial en tanto la ubicuidad adquiere un carácter definitorio del riesgo, lo global deviene en ubicuo, lo cual significa un borramiento del diferencial geopolítico (situado y conflictuado) que media y modula su producción semiótica y material, así como también su experiencia.

Otro aspecto relevante relacionado con el nuevo prudencialismo tiene que ver con el trastocamiento que este implica en los mecanismos 
de gestión de los riesgos característicos del régimen welfarista (Vázquez, 2005). En este último, el gobierno de los riesgos estaba implantado en la red de dependencia que vinculaban al ciudadano social con la colectividad y cuya forma emblemática es el sistema de cotizaciones a la seguridad social que permite prevenir múltiples eventualidades (enfermedades, desempleo, etc.). El dispositivo de solidaridad, a diferencia de su predecesor, no se fundamenta en la culpa sino en el riesgo y su principal instrumento no es el derecho, sino el seguro. Ewald (1997) señala que "La racionalidad que es el fundamento del riesgo lleva a modificar la forma de interpretar el problema de la imputación jurídica de los daños" (p. 16). La escisión entre la causalidad y la imputación conducirá a la institucionalización de un principio de imputación que no se refiere ya a la causalidad objetiva de los daños, sino en términos de «reparación». Se trata de un riesgo socializado, lo que quiere decir distribución del riesgo, o reparto social de las cargas. En este sentido el problema de la responsabilidad ya no es determinar "de quién es la culpa", sino a quién se tendrá que imputar el daño, quién tendrá que soportar la pérdida causada por accidente. En definitiva, un problema de equidad formulado en términos más económicos que morales. La fuente y el fundamento de la responsabilidad se desplazan del individuo a la sociedad: se es responsable no porque se es libre por naturaleza y porque se hubiese podido actuar de otra manera, sino porque la sociedad estima justo hacerle responsable, o sea, decidir quién soporte la carga monetaria del daño, independientemente de que sea autor o víctima. Esta es la lógica que se ha trastocado, en la medida que los procedimientos de significación, y en particular, el sujeto del riesgo, tiende a ser remplazado por la autorresponsabilidad. Esto significará al menos dos cosas.

En primer lugar, como ya hemos advertido en párrafos anteriores, el individuo ha de hacerse cargo de prevenir sus infortunios contratando los servicios pertinentes en un mercado; llámese fondo de pensiones, seguros de accidentes, compañías sanitarias, sistemas de seguridad, kit de prevención, etc. Más aún, el sujeto debe de desarrollar conductas de cálculo, autodisciplina y previsión, debiendo ser prudente en relación con su propia salud corporal y mental, prudente también con su futuro laboral y con su seguridad particular (Vázquez, 2005). Este desplazamiento en la 
significación del riesgo es indisociable del proceso de erosión de los sistemas de protección social que se habían desplegado en la sociedad salarial sobre la base de condiciones de trabajo estable. Indisociable también, de los procesos de individualización y descolectivización asociados a las transformaciones en el mundo del trabajo experimentadas en las últimas tres décadas.

En segundo lugar, en la medida que se fragiliza la lógica de la causación, el espectro del sujeto soberano de la decisión racional retorna y, junto a ello, una nueva ola de moralización recaerá sobre sus faltas. En efecto, si bien la epistemología de la relatividad se articula sobre una ética compleja y escéptica del sí mismo, al mismo tiempo, y de forma contradictoria, se retorna a una noción tradicional de la responsabilidad en tanto esta refiere a la renuncia de transferir a otro el peso de lo que ocurre a uno (salvo en el caso que se debiera a la culpa de otro). Se trata de una lógica liberal y neoconservadora que considera al individuo soberano en su decisión, propietario de su cuerpo, reivindicativo del derecho inalienable al placer (Preciado, 2002).

En este sentido, en el marco de la culpa, se observa el retorno del principio de responsabilidad el cual hará las veces de conversor universal del mal en bien. El individuo debe de ser tan previsor como prudente. Previsor en cuanto a las incidencias de la contingencia (antes llamada fortuna) y prudente en cuanto a sí mismo y a las consecuencias de sus actos. Previsor y prudente, el individuo no tiene excusas, razón por lo cual de toda y cualquier falta se ha de responsabilizar.

Ahora bien ¡cuáles son las implicancias políticas y epistémicas asociadas al principio de autorresponsabilidad? A modo de ejemplo, en el campo del delito, como señala David Garland (2005), esto va significar que se produzca la conjunción diferencial de dos figuras contradictorias del delito (la falta); por un lado, criminología del sí mismo para la cual el individuo que delinque es un sujeto racional y normal. Esto quiere decir que los "delincuentes" no son distintos del resto de nosotros y por tanto deben ser objeto de políticas incluyentes (normalización). Por otro lado, la criminología del otro, del desafiliado, del atemorizante, el extraño amenazante, el resentido y excluido, para la cual el individuo que delinque, 
el "delincuente", será considerado como "monstruo", un sujeto distinto a nosotros y de esta manera un candidato listo para la exclusión y la coerción (O`Malley, 2007). "Una es invocado para hacer del delito algo cotidiano, reducir los temores desproporcionados y promover acciones preventivas. La otra es utilizada para demonizar al delincuente, expresar los miedos e indignaciones populares y promover el apoyo al castigo estatal" (Garland, 2005, p. 232).

Como puede observarse, queda excluida una tercera posición intermedia entre esos dos polos, posición que hasta hace pocos años ocupaba la criminología welfarista, la cual describía al individuo que delinquía o al delincuente como una persona desfavorecida y escasamente socializada. De acuerdo a esta última lógica, sobre la base de un paradigma solidario, se transfería la responsabilidad hacia el Estado quien, a través de la política penal como de la política social, debía llevar adelante medidas destinadas a remediar dicha situación.

Más allá del campo penal, este tipo de racionalidad del riesgo opera con igual o mayor intensidad en otros campos. Así, por ejemplo, en el de la salud pública, la noción de "estilo de vida", desprovista de su carga sociológica "dura", funge como una categoría (factor de riesgo) descriptiva y predictiva, articulada sobre unos supuestos teóricos (ej. Teoría de acción racional) y axiológicos (soberanía y libertad individual) que modulan la significación del riesgo conforme a una práctica divisoria consistente con la descrita anteriormente (criminología del otro y del sí mismo). En efecto, en el marco del neoprudencialismo contemporáneo, el estilo de vida se codifica sobre la base de un modelo de la responsabilidad que oscilará entre el exceso (el todo) y la renuncia (el punto cero), pasando por su punto vinculado a una ética del cuidado de sí. Ahora bien, como antes hemos señalado, el modelo neoprudencial atribuye al sujeto la responsabilidad de gestionar sus propios riesgos, de autoproveerse seguridad a través de acciones positivas, basadas en su cálculo (previsión). Esto presupone que los individuos son sujetos racionales que han internalizado el cálculo de riesgo y que se han implicado de forma activa en el modelado de sus vidas conforme al ethos de la precaución. Para ello se implementarán una serie de dispositivos pedagógicos a través de los cuales se dotará a los individuos 
de un equipamiento semiótico-material para que estos puedan gestionar de forma eficaz los riesgos. La puesta en escena de la pedagogía del riesgo se realiza mediante un package formativo que interviene a nivel cognitivo, conductual y actitudinal a través de la entrega de información basada en evidencias científicas disponible en dicho campo, el entrenamiento individual o grupal de habilidades y una serie de kits preventivos con los cuales los individuos se tendrán que familiarizar para poder automonitorear sus comportamientos.

En este marco neoprudencial ¿cómo se entienden y cómo se significan los comportamientos de riesgo? O más aun ¿cómo se significan los daños asociados a dichos comportamientos? Obviamente responder a estas interrogantes no es tarea sencilla, y no se puede dar una respuesta unívoca y absoluta, pues estas varían dependiendo del contexto y de la situación en particular, es decir, varían conforme el universo de referencia. Así y todo, si nos atenemos a la relación estilo de vida y comportamiento de riesgo, bajo los supuestos que hemos descrito, veremos que la falta, la transgresión, dependiendo de su valoración moral, puede ser significada como una falla en los mecanismos de autocontrol, falla que puede referir a su inconsistencia, a su ausencia, o lisa y llanamente a su perversión (exceso). Ahora bien, si la superficie de inscripción de la falta o transgresión tiene que ver con un territorio altamente moralizado -como es el uso de drogas o el comportamiento sexual- pues entonces, en los dos últimos casos, es decir, en los sujetos a los que se les supone una ausencia de control o una perversión, la falla remite a una cuestión intrínseca, inscrita en su naturaleza "monstruosa", solo posible de controlar mediante su segregación. Piénsese en prácticas relacionadas con la reinfección a propósito de dos imágenes o íconos de sujetos de riesgo en el imaginario neoprudencial; en el caso de ausencia de control, nos referimos al "yonki de calle" el que no pudiendo aplazar o diferir en el tiempo su autosatisfacción, se inyecta tan pronto tiene la posibilidad de hacerlo, sin reparar en demasía en las condiciones sociales y sanitarias en las que realiza su práctica. Y en el segundo caso, nos referimos, por ejemplo, a las practicantes de barebacking (sexo a pelo) sobre todo en su variante bugchasing, entendiendo esta última como el acto de llevar a cabo sexo bareback cuando uno de los participantes presenta 
estatus serológico positivo y el otro no. En este acto sexual, el participante con estatus serológico negativo -denominado como bugchaser- busca de modo premeditado ser infectado por su compañero sexual -designado como giftgiver (Luna, 2010).

Ahora bien, desde una perspectiva neoprudencial, se va a sostener que ambos comportamientos son expresión de unos sujetos refractarios a la información e incluso a los servicios que podrían aminorar o modificar dichos comportamientos. Hipotéticamente hablando, ambos sujetos, previendo los riesgos y posibles daños, e incluso disponiendo de medios para poder modificar sus comportamientos o evitar ciertas consecuencias negativas altamente probables (salas de venopunción, uso de preservativos), deciden por voluntad propia continuar con determinado comportamiento. Por tanto, la pregunta que surge lógicamente desde esta perspectiva es ja quién imputar los daños? ¿Quién debe soportar la carga de estos? Como podemos ver aquí en estos casos la frontera entre responsabilización y la culpabilización es muy difusa. Si la falta remite a una falla en los sistemas de autocontrol, esto puede deberse a una debilidad o deficiencia en el equipamiento preventivo de que dispone el individuo, o a una falla atribuible a la irrupción de las contingencias no contempladas en el curso de la acción. En cualquiera de los casos, el individuo no queda exento de responsabilidad, pues debería haber previsto las posibles derivas del curso de su acción y haber tomado las medidas de precaución de forma oportuna. En consecuencia se deberá potenciar y reforzar la programación preventiva de la que será objeto y sujeto a la vez. Sin duda, esto no podrá hacerse sin la implicación activa del propio individuo, el que deberá desplegar una serie de prácticas orientadas al cuidado de sí. Sin embargo, estas no son "algo que el individuo mismo invente. Se trata de esquemas que encuentra en su cultura y que le son propuestos, sugeridos, impuestos por dicha cultura, su sociedad y su grupo social" (Foucault, 1999, p. 404). En cualquier caso, ambas figuras, pese a su excepcionalidad, lejos de ser secundarias, ocupan un lugar central pues, entre otras cosas, sirven para recrear dos ficciones necesarias para el mantenimiento del orden sociopolítico establecido y su imaginario neoprudencial: la ficción de la libertad y la ficción de la racionalidad del sistema (Álvarez-Uría, 2000). 


\section{Referencias}

Álvarez-Uría, F. (2000). Capitalismo y subjetividad. La teoría política y social de Michel Foucault. En P. López \& J. Muñoz (Eds.). La impaciencia de la libertad: Michel Foucault y lo político, (pp. 85-106). Madrid: Editorial Biblioteca Nueva, S.A.

Ampudia de Haro, F. (2006). Administrar el yo: literatura de autoayuda y gestión del comportamiento y los afectos. Revista Española de Investigaciones Sociológicas, 113, 49-75.

Beck, U. (1998). La sociedad del riesgo. Hacia una nueva modernidad. (J. Navarro, D. Jiménez \& Ma . Borras Trads.) Barcelona: Ediciones Paidós Ibérica S.A. (Trabajo original publicado en 1986).

Deleuze, G. (1999). Conversaciones (3a Ed.). (J.L. Pardo Trads.) Valencia: Editorial Pretextos. (Trabajo original publicado en 1990).

Deleuze, G. \& Guattari, F. (2002). Mil mesetas: Capitalismo y esquizofrenia (5 Ed.). (J. Vázquez Trads.) Barcelona: Editorial Pre-Textos. (Trabajo original publicado en 1980).

De Marinis, P. (1999). Gobierno, Gubernamentalidad, Foucault y los Anglofoucaultianos. Un Ensayo sobre la Racionalidad Política del Neoliberalismo. En F. García. \& R. Ramos (Eds.). Retos Actuales de la Teoria Social: Globalidad, Reflexividad y Riesgo, (pp. 73-103) Madrid: Centro de Investigaciones Sociológicas.

Douglas, M. (1991). Pureza y peligro. (E. Simons Trads.) Madrid: Siglo XXI. (Trabajo original publicado en 1966).

Ewald, F. (1997). Filosofía de la Precaución. Fundación MAPFRE. Gerencia de riesgos, 58, 13-30.

Foucault, M. (1999). Estética, ética y hermenéutica. (A. Gabilondo Trads.) Obras Esenciales. Volumen III. Barcelona: Paidós. (Trabajo original publicado en 1994).

Foucault, M. (2006). Seguridad, territorio y población. (H. Pons Trads.) Buenos Aires: Fondo de Cultura Económica. (Trabajo original publicado en 2004).

Gamma, A., Jerome, L., Liechti, M. E. \& Sumnall, H. R. (2005). Is ecstasy perceived to be safe? A critical survey $[¿$ Es el éxtasis percibido como seguro? Un estudio crítico]. Drug and Alcohol Dependence, 77(2), 185-193.

Garland, D. (2005). La cultura del control (M. Sozzo Trads.). Barcelona: Editorial Gedisa. (Trabajo original publicado en 2001).

Hacking, I. (1991). La domesticación del azar. La erosión del determinismo y el nacimiento de las ciencias del caos (A. Vixio Trads.). Barcelona: Editorial Gedisa. 
Leflaive, G. (2004). Consumo de drogas ilícitas: Estilo de vida, riesgos y realidades. Politica y Sociedad, 42(2), 203-221.

Luna, L. (2010). Evaluación actitudinal y conceptos asociados al Bareback en hombres que tienen sexo con otros hombres en la Ciudad de México. Revista Salud \& Sociedad, 1(1), 041-050.

Lupton, D. (1993). Riesgo como peligro moral: las funciones política y social del discurso del riesgo en salud pública. International Journal of Health Services, 23(3), 425-435.

O`Malley, P. (2007). Experimentos en gobierno. Analíticas gubernamentales y conocimiento estratégico del Riesgo. Revista Argentina de Sociología, 8(5), 152-171.

O’Malley, P. (1996). Risk and responsibility. En A. Barry, T. Osborne \& N. Rose (eds.): Foucault and political reason. Liberalism, neo-liberalism and rationalities of government, (pp. 189-207). Londres: UCL Press.

Preciado, B. (2002). Manifiesto contra-sexual. Madrid: Editorial Opera Prima.

San Martín, D. (2009). El riesgo como dispositivo de gobierno en la sociedad de control. En La globalización en crisis. Gubernamentalidad, control y politica de movimiento, (pp. 51-68). Cuaderno- Herramienta/02, Universidad Libre Experimental, Málaga.

Sepúlveda, M. (2011). El riesgo como dispositivo de gobierno en el campo de las drogas: Exotización, vicio y enfermedad. Disertación doctoral no publicada. Universidad Rovira i Virgili. Tarragona. España.

Vázquez, F. (2005). Empresarios de nosotros mismos. Biopolítica, mercado y soberanía en la gubernamentalidad neoliberal. En Ugarte, Javier (coord.) La administración de la vida. Estudios de biopolitica, (pp. 38-57) España: Anthropos.

Fecha de recepcion: 03 de noviembre de 2011.

Fecha de aceptacion: 15 de diciembre de 2011 